(2) Open Access Full Text Article

ORIGINALRESEARCH

\title{
Assessment of Male Involvement in Long-Acting and Permanent Contraceptive Use of Their Partner in West Badewacho, Southern Ethiopia
}

This article was published in the following Dove Press journal: Open Access Journal of Contraception

\author{
Abera Abose' \\ Girmay Adhena $\mathbb{D i D}^{2}$ \\ Yadeta Dessie ${ }^{3}$ \\ 'Department of Reproductive Health, \\ West Badewacho, Ethiopia; ${ }^{2}$ Department \\ of Reproductive Health, Tigray Regional \\ Health Bureau, Tigray, Ethiopia; ${ }^{3}$ School \\ of Public Health, College of Health and \\ Medical Science, Haramaya University, \\ Harar, Ethiopia
}

Background: Male involvement in family planning use particularly in long-acting and permanent contraceptive methods (LAPCM) is a key strategy to reduce fertility, and promote maternal and child health. Despite this, little is known about male involvement in LAPCM use of their partners in Africa, particularly in Ethiopia. This study aimed to assess male involvement in long-acting and permanent contraceptive method use in west Badewacho district, Southern Ethiopia.

Methods: A community-based cross-sectional study was conducted among 564 participants from April 1 to 30/2019. A multi-stage sampling technique was used to select eligible participants. A pre-tested, structured, and interviewer-administered questionnaire was used. Binary and multivariable logistic regression analysis was done to identify associated factors. The adjusted odds ratio with $95 \%$ CI was estimated to show the direction and strength of the association. Variables with $\mathrm{p}<0.05$ were considered statistically significant.

Results: About 108 (19.9\%, 95\% CI: $(16.8,23.2))$ participants were involved in LAPCM use. Being urban dweller [AOR=3.13; 95\% CI: $(1.58,6.19)]$, discussion with wives about LAPCM [AOR=2.81; 95\% CI: $(1.64,4.8)]$, having good knowledge about LAPCM [AOR=2.55; 95\% CI: $(1.42,4.57)]$, and positive attitude towards LAPCM [AOR=2.16; $95 \%$ CI: $(1.16,4.02)]$ were significantly associated factors.

Conclusion: Overall, the male involvement in LAPCM use was low. Enhancing male involvement in family planning use through creating community awareness, encouraging inter-spousal communication to enhance decision making, and increasing positive attitude towards LAPCM in the community is crucial to decrease the problem.

Keywords: male involvement, long-acting contraceptive, permanent contraceptive, Ethiopia

\section{Background}

Male involvement in family planning refers to when the men accept, discuss, and support their partner's needs, choices, and rights in fertility regulation methods and sexual behaviors. ${ }^{1}$ Male involvement in family planning use particularly in longacting and permanent contraceptive methods is key strategies to reduce fertility and promote maternal and child health. ${ }^{2}$ It is crucial to the success of family planning programs and women's empowerment and associated with better outcomes in reproductive health such as contraceptive acceptance, continuation, and safer sexual behaviors. $^{3}$

Contraceptives are used by the majority of married women, and evidence showed that $63 \%$ of married women worldwide used some form of contraceptive, 
and $58 \%$ of them used modern contraception methods. ${ }^{2-4}$ Even though the involvement of the male partner in the globe is low, long-acting and permanent contraceptive methods (LAPCM) are more effective, save costs, and enable women to control their reproductive lives better. ${ }^{4}$ This method accounted for about $56 \%$ of contraceptive use globally. Nineteen percent of married or in-union women relied on female sterilization, and about $14 \%$ used an intrauterine device (IUD). Yet most contraceptive users in Africa depend on short term methods. ${ }^{5}$ Evidence showed that short-acting contraceptives using women were 21 times more likely to have an unintended pregnancy than women using long-acting reversible and permanent methods. ${ }^{6}$

The unmet need for modern contraceptives was much higher in less developed regions, about $15 \%$ in Oceania, and $22 \%$ were in Africa. ${ }^{7,8}$ In the developing world, 74 million women each year have an unintended pregnancy. ${ }^{9}$ A projection in sub-Saharan African (SSA) countries indicated that more than 1.8 million unintended pregnancies would have been averted if $20 \%$ of women using oral contraceptives and injectable shifts to the implant. ${ }^{10}$ If the unmet need for family planning is fulfilled, it would prevent about 52 million unintended pregnancies, 500,000 newborn deaths, and 70,000 maternal deaths per year. ${ }^{11}$ Countries in sub-Saharan Africa have documented fertility rates of over 5 children per woman and the fastest average growth rate of $2.5 \%$ per year. ${ }^{12}$ The world's largest regional percentage increase in population will be in Africa, which expects about 2.3 billion, from this sub-Saharan Africa (SSA) expected to be 1.96 billion by the year $2050 .{ }^{13,14}$

Ethiopia has made several important international commitments to improve sexual and reproductive health but the service has been amongst the lowest in Africa. ${ }^{15}$ It is the fast-growing, second most popular nation in Africa. ${ }^{16}$ The total fertility rate of the country is 4.6 , with the highest in a rural region, and least-educated families. Despite contraceptive utilization increase internationally, Ethiopia's current contraceptive prevalence rate (CPR) remains $36 \%$, from which LAPCM accounts for only $10.4 \%$, of which $0.4 \%$ female sterilization, $2 \%$ IUCD, and $8 \%$ implants which are lowest compared to globally, and unmet need for contraceptives remains high $22 \% .{ }^{15}$ This unmatched expansion of human numbers creates a range of social, economic, and environmental challenges which is associated with high maternal, infant, and child morbidity, mortality rates, and other related problems. ${ }^{17}$
Due to a lack of open discussion between the couple about reproductive health issues, many women do not know what their partners think about family planning use. ${ }^{18,19}$ Lack of knowledge, myths, misconceptions, lack of access, desire to have more children, fear of social disapproval, worries of side effects, husband's opposition and religious prohibition, and negative attitude are among the main barriers in the male involvement of long-acting and permanent contraceptive method (LAPCM) use in Ethiopia. $^{20-22}$

For many years most family planning programs including research have focused attention primarily on women and offered their services exclusively to women. This has reinforced the belief that family planning is largely a woman's business and gave little attention to the role of men concerning women's reproductive health decisionmaking and behavior. ${ }^{23}$ In Ethiopia, studies were conducted at a male involvement point of understanding for their contribution to short-acting family planning use. However, little is known about male involvement in LAPCM use of their partners. Thus, this study was aimed to assess male involvement in LAPCM use in West Badewacho, Southern Ethiopia.

\section{Methods}

\section{Study Area and Period}

The study was conducted in the west Badewacho district, Southern Ethiopia. It is located 353 kilometers away from Addis Ababa, the capital city of Ethiopia. The district has a total of 22 kebeles, 20 rural and 2 urban kebeles. Based on the 2007 census population projection, the total population of the district was 110,702 of which about 56,458 $(51 \%)$ were female and 54,244 (49\%) were male. The contraceptive prevalence rate in the district was $51 \%$ and the prevalence of long-acting and permanent contraceptive methods was $9 \% .{ }^{24}$ The study was conducted from April 1-30/2019.

\section{Study Design}

A community-based cross-sectional study design was conducted.

\section{Population}

All husbands whose wives in the age group of 15-49 years old living in West Badewacho district were the source population. All husbands whose wives in reproductive age (15-49) of the selected kebeles constituted the study 
population. Currently, married men whose wives age 15-49 years and who were regularly living in the study area for at least six months and men living together with their wives were included. Men who were critically ill during the study period were excluded.

\section{Sample Size Determination and Sampling Procedures}

The sample size was calculated for the first objective by using the single population proportion formula $\left(\mathrm{n}=(\mathrm{z \alpha} / 2)^{2}\right.$ $\left.\mathrm{p}(1-\mathrm{p}) / \mathrm{d}^{2}\right)$ where $\mathrm{n}$ is the desired sample size, $\mathrm{P}(11.5 \%)$ is the prevalence of male involvement in LAPM, from the previous study done in Mizan-Aman Town, ${ }^{25} \mathrm{Z}$ is the critical value at $95 \%$ confidence level of certainty (1.96), $\mathrm{d}$ is the margin of error $(5 \%)$. Then based on the formula $\mathrm{n}=(1.96)^{2} * 0.115 * 0.885 /(0.05)^{2}=157$, assuming $10 \%$ nonresponse rate, $157+157 * 10 \%=173$ and considering 2 for design effect $173 * 2=346$. The sample size was also calculated for the second objective (factor) using Epi-info software version 7 , power $80 \%$, and $95 \%$ level of confidence and it gives 564. Finally, sample sizes calculated for the second objective (564) were greater than the sample size calculated for the first objective (346). Thus, the final sample size used for this study was 564 .

For the sampling procedure, there were 24 kebeles in the district. First kebeles were clustered us urban and rural kebeles then 6 kebeles from rural and one kebele from urban were selected using a simple random (lottery) method. The number of the household for each kebele was seen from the registration book of the health office, kebele as well as the health extension workers. Allocation of proportion to the sample size was done to identify the required number of households for each selected kebele. A systematic sampling method was employed to select the household from each kebele. After that, the first household was selected from the house of respective kebele using the lottery method, and the next household was identified using a systematic sampling technique. When more than one eligible respondent was found in the selected household, only one respondent was chosen by the lottery method. In cases where eligible was not found in the selected household, a revisit has been arranged a minimum of three times, and finally if they were not present considered as non-respondent.

\section{Data Collection Tools and Procedures}

The data were collected using pretested, structured and interviewer-administered questionnaires which were adapted and developed with modification from similar previous studies. ${ }^{15,25}$ It includes socio-demographic characteristics, economic status, reproductive characteristics, knowledge, attitude, and practices towards long-acting and permanent contraceptive use. It was first prepared in English and then translated into Hadiya (local language) by the language expert (person) to check its consistency, the questionnaire was translated back to English by another language expert. Data were collected by seven high school graduate male students who were residing in the study area and supervised by two-degree holder health professionals who were fluent speakers in the local language Hadiya. House to house data collection and a revisit has been arranged a minimum of three times. Intensive supervision was done by the principal investigators and supervisors throughout the data collection period.

\section{Operational Definition Knowledge}

This was measured by 10 knowledge of LAPCM items, and those who scored above $67 \%$ had high knowledge. Those who scored $33-67 \%$ had moderate knowledge, and those who scored below 33\% were categorized as they have low knowledge about LAPCM. $^{25}$

\section{Attitude}

Measured by 7 attitude items and those who scored above $67 \%$ of attitude questions of LAPCM had a positive attitude, those who scored from $33-67 \%$ had an indifferent way, and those who scored below 33\% grouped as they had a negative attitude. ${ }^{25}$

\section{Male Involvement}

Measured by four-questions that had a yes or no response. Respondents were categorized as involved for those who had participated in at least one, and not involved for those who did not participate in the for items. ${ }^{25,26}$

\section{Data Quality Assurance}

To assure the quality of the data, a structured and pretested questionnaire was used. The pretest was done among 28 $(5 \%)$ currently married men at Jarso kebele which is out of the study area. Based on the pre-test of the questionnaire, the necessary modifications and corrections took place to ensure its validity. The final version of the questionnaire was made from the English language to the local language Hadiya and back-translated to the English language by 
language experts to ensure its consistency. Two days of training was given for data collectors and supervisor and regular follow-up was done to check the collected data for completeness, accuracy, and consistency throughout the data collection period.

\section{Data Processing and Analysis}

The data were coded, checked, entered, and cleaned using Epi-Data 3.1 version software and exported into SPSS version 22 for analysis. The wealth index was constructed using principal component analysis (PCA) by considering locally available household assets to assess economic status. The outcome variable was recoded to dichotomous outcomes either they are involved or not. The male involved was coded as 1 and not involved were coded as ' 0 '. Univariate analysis such as simple frequency, a measure of central tendency, and a measure of variability was used to describe the characteristics of participants, and information was presented using tables, narratives, and figures. Bivariate analysis was done to see the association between the independent variable and the outcome variable. Independent variables with a p-value of $<0.25$ were the candidate for the multi-variable analysis to control confounding factors. Multi-collinearity was checked to see the linear correlation among the independent variables. Hosmer-Lemeshow test was found to be insignificant at ( $\mathrm{p}$-value $=0.79)$ and omnibus tests were significant ( $p$-value $\leq 0.001$ ) which indicated the model was fitted. The adjusted odds ratio along 95\% CI was estimated to show the strength and direction and the level of statistical significance was considered at a p-value $<0.05$.

\section{Ethical Consideration}

Ethical clearance was secured from the Haramaya University College of Health and Medical Science Institutional Health Research Ethics Review Committee (IHRERC). The official letter was sent to the West Badewacho district, and the data collection was begun after a permission letter was written to all selected kebeles. The study purpose, procedure, possible risks, and benefits of the study were explained for each participant. Informed, volunteer, signed, and written consent was obtained from each participant. The respondents were assured of confidentiality by excluding their names during the period of data collection. They were informed well that they have the full right to refuse to participate and/or withdraw from the interview at any time if they have any difficulty.

\section{Results}

\section{Socio-Demographic Characteristics of Study Participant}

From a total of 564 expected participants, 543 were interviewed making a response rate of $96.3 \%$. The mean age of the participants was $34.5(\mathrm{SD} \pm 7)$ years old. Near half of the respondents, $256(47.1 \%)$ were in the age group of 31 to 40 . About three-fourth, 412 (75.9\%) of respondents were Hadiya in their ethnicity. The majority, 418 (77.0\%) of respondents were protestant followers in their religion and $475(87.5 \%)$ were rural dwellers. Regarding their educational status, about 84 (15.5\%) never attended formal education, $128(23.6 \%)$ were able to read and write, $148(27.3 \%)$ attended primary education and $183(33.7 \%)$ attended secondary and above education. More than half, 287 (52.9\%) were farmers, more than one fourth, $141(25.9 \%)$ were merchants, and the majority, $444(81.7 \%)$ of participants had lower quartile economic status (Table 1).

\section{Reproductive Characteristics of Respondents}

Among study participants, the average number of total and currently living children was 4.86 , and 4.22 per man respectively, while the average desired number of children was 5.46 per man. The majority of respondents, 486 (89.5\%) wished to have more children, out of this number, about $42.38 \%$ of them want by the preference of the male child. Thirty percent of the respondents preferred to have the next child within 2 years gap, while, $42.5 \%$ and $27.5 \%$ of the respondents wished to have their next child between 2 and 3 years and after 3 years old gaps respectively (Table 2).

\section{Male Involvement in LAPCM Use}

Among 543 participants, 108 (19.9\%, 95\% CI: (16.8, 23.2)) were involved in the LAPCM use of their partner (Figure 1). About 98 (18.0\%) of respondents' wife were utilized LAPCM, 99 (18.2\%) participants support their partner, and others use LAPCM, and 87 (16\%) of participants gone to the health facility with their wife to discuss LAPCM use with the health care provider.

\section{Awareness to LAPCM-Related Characteristics of Respondents}

About 486 (89.5\%) respondents reported that they heard about LAPCM. The most commonly known LAPCM reported by study participants was Implant 483 (99.4\%), followed by 
Table I Sociodemographic Characteristics of Respondents in West Badewacho District, Hadiya Zone, Southern Ethiopia, $2019(N=543)$

\begin{tabular}{|c|c|c|c|}
\hline Variable & Categories & Frequency & Percentage \\
\hline \multirow[t]{3}{*}{ Age (Year) } & $20-30$ & 187 & 34.4 \\
\hline & $31-40$ & 256 & 47.1 \\
\hline & $>40$ & 100 & 18.5 \\
\hline \multirow[t]{2}{*}{ Residence } & Urban & 68 & 12.5 \\
\hline & Rural & 475 & 87.5 \\
\hline \multirow[t]{4}{*}{ Ethnicity } & Hadiya & 412 & 75.9 \\
\hline & Kembata & 88 & 16.2 \\
\hline & Wolaita & 34 & 6.3 \\
\hline & Others & 9 & 1.7 \\
\hline \multirow[t]{4}{*}{ Religion } & Protestant & 418 & 77.0 \\
\hline & Catholic & 62 & 11.4 \\
\hline & Orthodox & 52 & 9.6 \\
\hline & Muslim & II & 2.0 \\
\hline \multirow[t]{4}{*}{$\begin{array}{l}\text { Educational } \\
\text { status }\end{array}$} & $\begin{array}{l}\text { No formal } \\
\text { education }\end{array}$ & & \\
\hline & Primary school & 275 & 50.6 \\
\hline & Secondary school & 117 & 21.6 \\
\hline & $\begin{array}{l}\text { Diploma and } \\
\text { above }\end{array}$ & 62 & 11.4 \\
\hline \multirow{4}{*}{$\begin{array}{l}\text { Occupational } \\
\text { status }\end{array}$} & Farmer & 287 & 52.9 \\
\hline & Merchant & I4I & 25.9 \\
\hline & Employer & 81 & 14.9 \\
\hline & Daily laborer & 34 & 6.3 \\
\hline \multirow[t]{3}{*}{ Wealth index } & Low & 444 & 81.7 \\
\hline & Medium & 74 & 13.7 \\
\hline & High & 25 & 4.6 \\
\hline
\end{tabular}

IUCD 428 (88.06\%). But female sterilization 247 (50.8\%) and male sterilization $232(47.7 \%)$ was the least known reported methods. Among those who had ever heard about LAPMs, the majority 367 (75.5\%) of them had heard messages of LAPCMs in the last 12 months through the mass media, $63.3 \%$ got from health institutions, $60.3 \%$ got information from friends and $58.2 \%$ got from a family member. Participants were also asked about the advantage of LAPCMs, and about 443 $(91.2 \%)$ said for the spacing of childbirth, 351 (72.2\%) for preventing unwanted pregnancy, $319(65.6 \%)$ for limiting the number of children, and 201 (41.3\%) of respondents said it is used to reduce maternal and child death. This study asked about the LAPCM participants currently used method, the most commonly used method by the respondent's wives was implant 50 (51.01\%), and IUCD 42 (42.8\%), but no one underwent male sterilization in the study area. Forty percent of study participants discussed LAPCM use with their partner in the last
Table 2 Reproductive Characteristics of the Study Subjects, West Badewacho District, Hadiya Zone, Southern Ethiopia, 2019

\begin{tabular}{|c|c|c|c|}
\hline Variable & Categories & Frequency & Percentage \\
\hline $\begin{array}{l}\text { Number of } \\
\text { currently living } \\
\text { children }\end{array}$ & $\begin{array}{l}\leq 2 \\
3-4 \\
>4\end{array}$ & $\begin{array}{l}114 \\
209 \\
220\end{array}$ & $\begin{array}{l}21.0 \\
38.5 \\
40.5\end{array}$ \\
\hline $\begin{array}{l}\text { The respondents } \\
\text { desired number of } \\
\text { children }\end{array}$ & $\begin{array}{l}I-2 \\
3-4 \\
\geq 4\end{array}$ & $\begin{array}{l}1 \\
257 \\
285\end{array}$ & $\begin{array}{l}0.2 \\
47.3 \\
52.5\end{array}$ \\
\hline $\begin{array}{l}\text { Wanting more } \\
\text { children }\end{array}$ & $\begin{array}{l}\text { Yes } \\
\text { No }\end{array}$ & $\begin{array}{l}486 \\
57\end{array}$ & $\begin{array}{l}89.5 \\
10.5\end{array}$ \\
\hline $\begin{array}{l}\text { How many children } \\
\text { do you want in the } \\
\text { future }\end{array}$ & $\begin{array}{l}\mathrm{I}-2 \\
\geq 3\end{array}$ & $\begin{array}{l}373 \\
113\end{array}$ & $\begin{array}{l}76.7 \\
23.3\end{array}$ \\
\hline $\begin{array}{l}\text { Sex of the future } \\
\text { wanted a child }\end{array}$ & $\begin{array}{l}\text { Male } \\
\text { Female } \\
\text { No preference } \\
\text { Both equally }\end{array}$ & $\begin{array}{l}206 \\
65 \\
113 \\
102\end{array}$ & $\begin{array}{l}42.38 \\
13.37 \\
23.25 \\
20.98\end{array}$ \\
\hline Birth space & $\begin{array}{l}<2 \text { year } \\
2-3 \text { year } \\
>3 \text { year }\end{array}$ & $\begin{array}{l}163 \\
231 \\
149\end{array}$ & $\begin{array}{l}30.0 \\
42.5 \\
27.5\end{array}$ \\
\hline
\end{tabular}

twelve months. Regarding the decision on the current use of LAPCMs, $72(76.5 \%)$ of respondents made the decision jointly, while $20(20.7 \%)$ of the respondents decided by themselves, and $66.4 \%$ of current users of LAPCM were using for birth spacing (Table 3).

\section{Knowledge and Attitude to LAPCM of Respondents}

Nearly half $251(46.2 \%)$ and $233(42.9 \%)$ of married men aware there is an operation to prevent further pregnancy

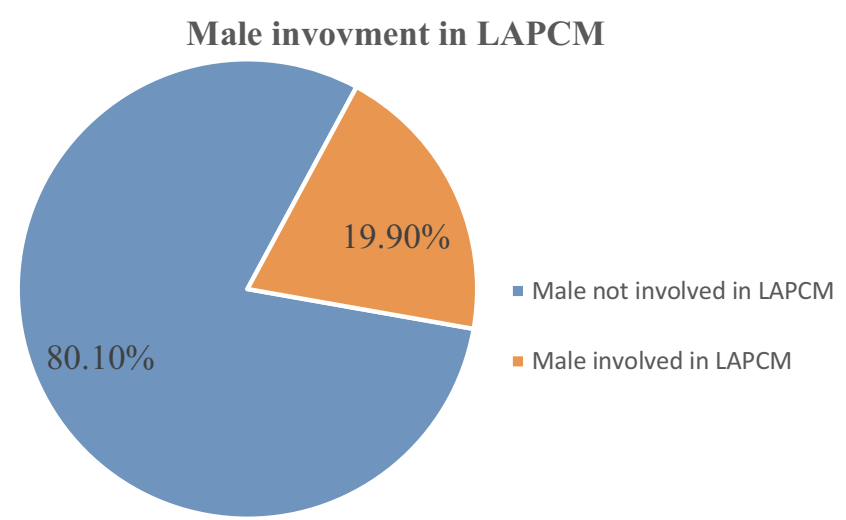

Figure I Male involvement in long-acting and permanent contraceptive methods use in West Badewacho, Southern Ethiopia, 2019. 
Table 3 Awareness-Related Characteristics of Respondents in the West Badewacho District, Southern Ethiopia, 2019 ( $n=543$ )

\begin{tabular}{|c|c|c|c|}
\hline Variable & Categories & Frequency & Percentage \\
\hline \multirow[t]{2}{*}{ Ever heard about LAPMs $(n=543)$} & Yes & 486 & 89.5 \\
\hline & No & 57 & 10.5 \\
\hline \multirow[t]{4}{*}{ Source of information about LAPMs $(n=486)$} & Health institution & 308 & 63.3 \\
\hline & Family member & 283 & 58.2 \\
\hline & Friends & 293 & 60.3 \\
\hline & Media & 367 & 75.5 \\
\hline \multirow[t]{4}{*}{ The benefit of using LAPCM $(n=486)$} & Prevent unwanted pregnancy & 351 & 72.2 \\
\hline & Reduce maternal and child death & 201 & 41.35 \\
\hline & For limiting & 319 & 65.6 \\
\hline & For spacing & 443 & 91.2 \\
\hline \multirow{4}{*}{ Type of LAPCMs know $(n=486)$} & Implant & 483 & 99.4 \\
\hline & IUCD & 428 & 88.06 \\
\hline & Female sterilization & 247 & 50.8 \\
\hline & Male sterilization & 232 & 47.7 \\
\hline \multirow[t]{2}{*}{ Ever use LAPCM $(n=543)$} & Yes & 175 & 32.2 \\
\hline & No & 368 & 67.8 \\
\hline \multirow[t]{2}{*}{ Reason for using LAPCM from current users $(n=98)$} & Birth spacing & 65 & 66.3 \\
\hline & Birth limiting & 33 & 33.67 \\
\hline \multirow[t]{2}{*}{ Discussion about LAPCM with partner } & Yes & 219 & 40.3 \\
\hline & No & 324 & 59.7 \\
\hline \multirow[t]{3}{*}{ Number of discussion with their wives about LAPCM $(n=219)$} & Once & 33 & 15.0 \\
\hline & Twice & 64 & 29.2 \\
\hline & Many times & 122 & 55.7 \\
\hline \multirow[t]{4}{*}{ Types of LAPM that are currently used $(n=98)$} & Implant & 50 & 51.01 \\
\hline & IUCD & 42 & 42.8 \\
\hline & Tubal ligation & 6 & 6.1 \\
\hline & Vasectomy & 0 & 0 \\
\hline \multirow[t]{3}{*}{ Whose choice is the current LAPCM use $(n=98)$} & My wife & 6 & 6.12 \\
\hline & Myself & 20 & 20.4 \\
\hline & Both of us & 72 & 76.5 \\
\hline \multirow[t]{6}{*}{ Responsibility of male in LAPCM utilization $(\mathrm{N}=543)$} & Supporting their wife to use LAPCM & 120 & 22.2 \\
\hline & Use the methods by themselves & 12 & 2.2 \\
\hline & Allocate a budget for it & 103 & 19.0 \\
\hline & Discussion with the wife about utilization & 219 & 40.3 \\
\hline & Know the advantages and tell the wife & 103 & 19.0 \\
\hline & Have no role & 391 & 72.3 \\
\hline
\end{tabular}

for both women and men respectively. More than half 298 $(54.9 \%)$ of respondents were aware that IUCD can prevent pregnancy for more than 10 years. One fourth $139(25.9 \%)$ of respondents were aware that IUCD cannot cause cancer. About 105 (19.5\%) of participants were aware that IUCD has no influence on sexual intercourse, and 292 (53.8\%) were aware of immediate pregnancy after removal of the contraceptive method (Table 4).
The attitude of participants on the LAPCM was assessed in this study and about 329 (60.6) participants agreed that the availability of family planning information and service for men is necessary. The majority of married men (70\%) believed that the sterilization of both men and women was no acceptable Above four-fifths (83.5\%) of married men beliefs that male sterilization cause impotence. About $71.4 \%$ of respondents' beliefs using IUCD restrict routine 
Table 4 Knowledge-Related Characteristics of Respondents in West Badewacho District, Hadiya Zone, Southern Ethiopia, 2019 $(n=543)$

\begin{tabular}{|c|c|c|c|}
\hline Knowledge of LAPCM Items & Yes (\%) & No (\%) & Not Sure (\%) \\
\hline Women have an operation to avoid any more child & $251(46.2)$ & $126(23.2)$ & $166(30.6)$ \\
\hline Men have the operation to avoid any more child & $233(42.9)$ & $144(26.5)$ & $166(30.6)$ \\
\hline IUCD inserted into uterus by midwife or nurse & $429(79)$ & $52(9.6)$ & $62(11.4)$ \\
\hline An implant placed in the upper arm by a health worker & $482(88.8)$ & $26(4.8)$ & $35(6.4)$ \\
\hline After sterilization pregnancy is possible & $106(19.5)$ & $170(31.3)$ & $267(49.2)$ \\
\hline IUCD causes to cancer & $81(14.9)$ & $139(25.6)$ & $323(59.3)$ \\
\hline IUCD and implant are immediately reversible & $292(53.8)$ & $59(10.9)$ & $192(35.4)$ \\
\hline IUCD prevent pregnancy for more than 10 years & $298(54.9)$ & $63(11.6)$ & $182(33.5)$ \\
\hline IUCD is appropriate for STI high-risk women & $92(16.9)$ & $71(13.1)$ & $380(70)$ \\
\hline IUCD interfere with sexual desire & $85(15.7)$ & $105(19.3)$ & $353(65)$ \\
\hline
\end{tabular}

Table 5 Attitude-Related Characteristics of Respondents in West Badewacho District, Hadiya Zone, Southern Ethiopia, 2019 $(\mathrm{N}=543)$

\begin{tabular}{|l|l|l|l|}
\hline Attitude Items Towards LAPCM & Yes (\%) & No (\%) & Not Sure (\%) \\
\hline LAPCM information and service should be available to men & $329(60.6)$ & $147(27.1)$ & $67(12.3)$ \\
Discussion about LAPCM with wife is necessary & $319(58.7)$ & $138(25.4)$ & $86(15.8)$ \\
Operation for male and female sterilization is acceptable & $163(30)$ & $210(38.7)$ & $170(31.3)$ \\
Using IUCD not restrict routine activity & $155(28.5)$ & $233(42.9)$ & $155(28.5)$ \\
Using IUCD and implant cause infertility & $121(22.3)$ & $230(42.4)$ & $192(35.4)$ \\
Men should share the responsibility for using LAPCM & $151(27.8)$ & $208(38.3)$ & $184(33.9)$ \\
Male sterilization cause impotence & $90(16.6)$ & $249(45.9)$ & $204(37.6)$ \\
\hline
\end{tabular}

activity and $77.8 \%$ of them beliefs using an implant and IUCD cause infertility for future life (Table 5).

\section{Factors Associated with Male Involvement in LAPCM Use}

In a bivariate analysis, residence, educational status, age of husbands, number of the living child, number of the child wanted in the future, birth spacing, ever heard information, history of using LAPCM, knowledge, and attitude was significantly associated with male involvement in LAPCM use. In the final model (multivariable analysis), discussion with wives, residence, high knowledge, and positive attitude towards LAPCM use were found significantly associated factors with male involvement in LAPCM use (Table 6).

\section{Discussion}

Overall, about 19.9\% (95\% CI: $(16.8,23.2))$ of participants were involved in LAPCM use. Being an urban resident, discussion with wives about LAPCM, having high knowledge, and a positive attitude towards LAPCM use were significantly associated factors.
The finding in this study (19.9\%) is higher than the study conducted in Bodit town (13\%), and Debre Markos town $(8.4 \%) .^{20,27}$ But it is lower than from a study conducted in Gedeo town (36\%), ${ }^{28}$ and Afar (42.2\%). ${ }^{29}$ The variation may be due to demographic, socio-cultural variation of the study subjects. For example, participants in the study in Bodit were urban residents which may know the family planning use whereas this study includes both rural and urban residents. The discrepancy could also be due to the definition, and time difference of the study. Some of the studies include male involvement in all family planning methods where this study focused only LAPCM this might decrease the magnitude of male involvement in LAPCM.

This study also assessed factors associated with male involvement in LAPCM use. Participants who have high knowledge of LAPCM were 2.55 times more likely involved in LAPCM than men who had low knowledge about LAPCM. This is consistent with a study done in Tigray, Bodit, Debre Markos, Gedio, and Afar. ${ }^{20,26,28,29}$ Men who have good knowledge about family planning may more likely have know-how about how to use contraceptives and play roles in couple contraceptive use and 
Table 6 Factors Independently Associated with Male Involvement in LAPCM Use of Their Partner in West Badewacho District, SNNPR, Ethiopia, $2019(\mathrm{~N}=543)$

\begin{tabular}{|c|c|c|c|c|}
\hline \multirow[t]{2}{*}{ Variables } & \multicolumn{2}{|c|}{ Male Involvement in LAPCM } & \multirow[t]{2}{*}{ COR $(95 \% \mathrm{Cl})$} & \multirow[t]{2}{*}{ AOR $(95 \% \mathrm{Cl})$} \\
\hline & Involved (\%) & Not Involved (\%) & & \\
\hline \multicolumn{5}{|l|}{ Residence } \\
\hline Urban & $36(52.9)$ & $32(47.1)$ & $6.29(3.67,10.7)$ & $3.13(1.58,6.19)^{*}$ \\
\hline Rural & $72(15.1)$ & $403(84.9)$ & 1 & 1 \\
\hline \multicolumn{5}{|l|}{ Educational status } \\
\hline Unable to read and write & $13(14.6)$ & $76(85.4)$ & 1 & 1.00 \\
\hline Primary & $36(13.0)$ & $239(87.0)$ & $0.88(0.44,1.74)$ & $1.03(0.45,2.33)$ \\
\hline Secondary & $29(24.8)$ & $88(75.2)$ & $1.92(0.93,3.96)$ & I.68 $(0.70,4.04)$ \\
\hline Higher education and above & $30(48.4)$ & $32(5 \mid .2)$ & $5.48(2.53,11.8)$ & $0.49(1.16,1.46)$ \\
\hline \multicolumn{5}{|l|}{ Occupational status } \\
\hline Farmer & $33(11.5)$ & $254(88.5)$ & $0.36(0.15,1.08)$ & $0.57(0.22,1.48)$ \\
\hline Merchant & $23(16.3)$ & II 8 (83.7) & $0.54(0.22,1.31)$ & $0.53(0.19,1.46)$ \\
\hline Employer & $43(53.0)$ & $38(47)$ & $3.14(1.30-7.56)$ & $2.08(0.74,5.83)$ \\
\hline Daily laborer & $9(26.5)$ & $25(73.5)$ & I & 1 \\
\hline \multicolumn{5}{|l|}{ Discussion about LAPCM } \\
\hline No & 37 (II.4) & $287(88.6)$ & 1 & I \\
\hline Yes & $71(32.4)$ & I $48(67.6)$ & $3.72(2.38,5.80)$ & $2.8 \mathrm{I}(1.64,4.8)^{* *}$ \\
\hline \multicolumn{5}{|l|}{ Ever used LAPCM } \\
\hline No & $50(13.5)$ & $320(86.5)$ & 1 & I \\
\hline Yes & $58(33.5)$ & $115(66.5)$ & $3.22(2.09,4.98)$ & $1.61(0.95,2.73)$ \\
\hline \multicolumn{5}{|l|}{ Number of living children } \\
\hline $\mathrm{I}-2$ & $35(69.3)$ & $79(30.7)$ & $2.05(1.21,3.48)$ & $0.94(0.43,2.03)$ \\
\hline $3-4$ & $34(16.3)$ & $175(83.7)$ & $0.9(0.54,1.49)$ & $0.82(0.43,1.57)$ \\
\hline$>4$ & $39(17.7)$ & $|8|(82.3)$ & 1 & 1 \\
\hline \multicolumn{5}{|l|}{ Wanting more child } \\
\hline No & $21(36.8)$ & $36(63.2)$ & $2.74(1.33,5.64)$ & I.8I $(0.73,4.43)$ \\
\hline $\mathrm{I}-2$ & $67(18.0)$ & $305(82.0)$ & $1.03(0.59,1.79)$ & $0.96(0.50,1.83)$ \\
\hline$>2$ & $20(17.5)$ & $94(82.5)$ & I & I \\
\hline \multicolumn{5}{|l|}{ Birth spacing } \\
\hline$<2$ & $21(12.5)$ & $146(87.5)$ & 1 & 1 \\
\hline $2-3$ & $43(18.6)$ & I88 (8I.4) & $1.59(0.90,2.79)$ & $0.97(0.49,1.91)$ \\
\hline$>3$ & $44(30.3)$ & $101(69.7)$ & $3.02(1.69,5.40)$ & $1.33(0.66,2.70)$ \\
\hline \multicolumn{5}{|l|}{ Knowledge status } \\
\hline High & $58(4 \mid .7)$ & $81(58.3)$ & $5.54(3.39,9.05)$ & $2.55(1.42,4.57)^{* *}$ \\
\hline Moderate & $16(14.9)$ & $91(85.1)$ & I.36 (0.7I, 2.58) & $0.89(0.43-1.86)$ \\
\hline Low & $34(11.4)$ & $263(88.6)$ & 1 & 1 \\
\hline \multicolumn{5}{|l|}{ Attitude } \\
\hline Positive & $55(54.0)$ & $47(46)$ & $4.92(2.98,8.11)$ & $2.16(1.16,4.02)^{* *}$ \\
\hline Indifferent way & $17(15.7)$ & 91 (84.3) & $1.16(0.63,2.13)$ & $0.77(0.38,1.54)$ \\
\hline Negative & $36(10.8)$ & $297(89.2)$ & I & I \\
\hline
\end{tabular}

Notes: *p-value $<0.05$;**p-value $<0.01$.

Abbreviations: $\mathrm{AOR}$, adjusted odds ratio; $\mathrm{Cl}$, confidence Interval; $\mathrm{COR}$, crude odds ratio.

continuation, due to this reason husband's background knowledge of family planning affects their involvement in LAPCM use.
Men who have a positive attitude towards family planning services were 2.16 times more likely to be involved in LAPCM utilization as compared to those who have 
a negative attitude. This finding is consistent with a study conducted in Debre Markos and Gedio. ${ }^{20,28}$ The possible reason could be due to those who have a positive attitude towards LAPCM may like the service and they might be interested to involve in their partners' family planning service. Whereas those who have a negative attitude to LAPCM may even refuse and violet their partner not only to involve but also they may also stop the family planning method used by their partner.

In this study men who had discussed with their wives about LAPCM use were 2.81 times more likely to involve in LAPMs use than those who did not discuss. This finding is consistent with studies done in Bodit, Mizan-Aman, Wolaita Soddo, Kenya, and Nigeria. ${ }^{25,27,30-32}$ This may be due to through discussion a couple can come to a mutual decision on whether or not to use contraception to plan when to have children and how many to have. Partners may know how to express their desires and feelings without any fears, and easily make out his/her spouse's attitudes and beliefs regarding LAPM which increases the involvement of the male partner.

Husbands who live in urban were 3.13 times more likely involved in LAPCM utilization compared to those who live in rural areas. This finding is consistent with a study conducted in Bangladesh and Southeast Nigeria. ${ }^{33,34}$ The possible reason could be due to urban residents tend to have higher literacy and socioeconomic status, enjoy better access to healthcare service, and receives greater media exposure, all of which are likely to improve knowledge of family planning, in general, this may increase the involvement of the partner in LAPCM.

\section{Limitation}

Since this study included only men, the practice of their spouses might be different from what is measured by this study, and there might be social-desirability of responses rather than actual knowledge or practices could be response biases.

\section{Conclusion}

Male involvement in long-acting and permanent contraceptive method use was low. Being an urban resident, discussion with wives about LAPCM, having a high knowledge of LAPCM, and a positive attitude towards LAPCM use were significantly associated factors. Enhancing male involvement in family planning use through creating community awareness, encouraging inter-spousal communication to enhance decision making, and increasing positive attitude towards LAPCM in the community is crucial to decrease the problem.

\section{Abbreviations}

$\mathrm{CPR}$, contraceptive prevalence rate; IUCD, intrauterine contraceptive method; LAPCM, long-acting and permanent contraceptive method; SSA, sub-Saharan Africa.

\section{Data Sharing Statement}

The data used for the findings of this study are available from the corresponding author upon reasonable request.

\section{Ethical Approval}

The study was conducted following the declaration of Helsinki on human subjects. After the purpose, benefit and risk were briefed, informed consent was obtained from the study participants. Ethical clearance was secured by Haramaya University Institutional Health Research Ethics Review Committee (IHRERC) and official permission was obtained from West Badewacho district health office and municipal.

\section{Acknowledgments}

We would like to appreciate Haramaya University. Our heartfelt thanks also extend to the staff of east Badichiwa, supervisors, data collectors, and the study participants for their willingness and cooperation in the data collection process.

\section{Author Contributions}

All authors made substantial contributions to conception and design, acquisition of data, or analysis and interpretation of data; took part in drafting the article or revising it critically for important intellectual content; agreed to submit to the current journal; gave final approval of the version to be published, and agree to be accountable for all aspects of the work.

\section{Disclosure}

The authors declare that they have no conflicts of interest in this work.

\section{References}

1. Abdel A, Amira O, Busby J, Gilbert R, Cahill DJ, Hollingworth W. Factors affecting unmet need for family planning in Eastern Sudan. BMC Public Health. 2013;13(1):112-165. doi:10.1186/1471-2458-13112 
2. Blumenthal P, Voedisch A, Gemzell-Danielsson K. Strategies to prevent unintended pregnancy: increasing use of long-acting reversible contraception. Hum Reprod Update. 2010;17(1):121-137. doi:10.10 93/humupd/dmq026

3. Joshi R, Khadilkar S, Patel M. Global trends in the use of long-acting reversible and permanent methods of contraception: seeking a balance. Int J Gynecol Obstet. 2015;131:S60-S3. doi:10.1016/j.ijgo. 2015.04.024

4. Winner B, Peipert J, Zhao Q, Buckel C, Madden T, Allsworth J. Effectiveness of long-acting reversible contraception. $N$ Engl J Med. 2012;366(21):1998-2007. doi:10.1056/NEJMoa11 10855

5. UN. United Nations Department of economic and social affairs population division. Trends in contraceptive use worldwide in 2015 2015.

6. Lotke P. Increasing use of long-acting reversible contraception to decrease unplanned pregnancy. Obstet Gynecol Clin N Am. 2015;42 (4):557-567. doi:10.1016/j.ogc.2015.07.008

7. United Nations. World family planning. 2017.

8. WHO. Global summit on family planning world health organization. 2017.

9. UNFPA. Choices do not chance UNFPA family planning strategy. 2017.

10. Hubacher D, Mavranezouli I, McGinn E. Unintended pregnancy in sub-Saharan Africa: the magnitude of the problem and potential role of contraceptive implants to alleviate it. Contraception. 2008;78 (1):73-78. doi:10.1016/j.contraception.2008.03.002

11. WHO. Family planning, and the post-2015 development agenda. 2015.

12. World Bank 2012. World Development Indicators. World Bank; 2012.

13. Hartmann M, Gilles K, Shattuck D, Kerner B, Guest G. Changes in couple's communication as a result of a male-involvement family planning intervention. J Health Commun. 2012;17:7. doi:10.1080/ 10810730.2011 .650825

14. Ader A, Belete T, Gebru A, Hagos A, Gebregziabher W. Assessment of the role of men in family planning utilization at edaga-Hamuse Town, Tigray, North Ethiopia. Am J Nurs Sci. 2015;4:4.

15. EDHS. Ethiopia Demographic and Health Survey. Addis Ababa, Ethiopia, and Rockville, Maryland, USA: CSA and ICF; 2016.

16. Population Reference Bureau. World Population Data. 2018.

17. John BJC. Fertility transition: is Sub-Saharan Africa different? Popul Dev Rev. 2012;38(SuPPlement):153-168.

18. Kamal I, Islam MA. Interspousal communication on family planning and its effect on contraceptive adoption in Bangladesh. Asia Pac J Public Health. 2012;24:3. doi:10.1177/1010539511399118

19. FMOH. The National Policy Guidelines and Service Standard for Reproductive Health Services. 2011.
20. Kassa A, Abajobir AA, Gedefaw M. Level of male involvement and associated factors in family planning services utilization among married men in Debremarkos town, Northwest Ethiopia. BMC Int Health Hum Rights. 2014;14:33. doi:10.1186/s12914-014-0033-8

21. Omar J, Roble S. Constructive men's engagement in reproductive health and HIV in Ethiopia, facilitating policy dialogue. Health Policy Initiative. 2011.

22. Gebremariam A, Addissie A. Knowledge and perception on long acting and permanent contraceptive methods in Adigrat town, Tigray, northern Ethiopia: a qualitative study. Int J Family Med. 2014;2014:1-6. doi:10.1155/2014/878639

23. Girum T, Shegaze M, Tariku Y. The role of currently married men in family planning and its associated factors in Agaro town, South West Ethiopia. Ann Med Health Sci Res. 2017;7.

24. CSA: Population and Housing Census of Ethiopia. The administrative report, Addis Ababa. 2007.

25. Mulatu K, Mekonnen W. Men's involvement in long-acting and permanent contraceptive use in Mizan-Aman District Southwestern Ethiopia: a community based cross-sectional study. Health Sci J. 2016;10(2):2.

26. Bayray A. Assessment of male involvement in family planning use among men in the south eastern zone of Tigray, Ethiopia. $J$ Med. 2012;2:1-10.

27. Tadesse M, Meskele M, Dana T. The role of male partner on current utilization of long-acting and permanent contraceptive methods in Bodit Town, Southern Ethiopia. J Health Med Nurs. 2016;33.

28. Dereje A, Abainew A, AbdoKurke K. Male involvement in family planning and associated factors among married male in Gedo Town West Shoa Zone, Oromia, Ethiopia. J Culture Soc Dev. 2016;15.

29. Chekole K, Medhanyie G, Medhanyie AA, Gebreslassie MA, Bezabh AM. Husbands' involvement in family planning use and its associated factors in pastoralist communities of Afar, Ethiopia. BMC $J$ Reprod Health. 2019;16:33. doi:10.1186/s12978-019-0697-6

30. Abraham W, Adamu A, Deresse D. The involvement of men in family planning an application of transtheoretical model in Wolaita SoddoTown South Ethiopia. Asian J Med Sci. 2010;2.

31. Irani L, Speizer SI, Jean- FC. Couple characteristics and contraceptive use among women and their partners in Urban Kenya. Int Perspect Sex Reprod Health. 2014;40:11-20. doi:10.1363/4001114

32. Oyediran KA. Husband-wife communication and couple's fertility desires among the Yoruba of Nigeria. Afr Popul Stud. 2014;17.

33. Ghos B, Shangfeng T, Sanni Y, Ide S. Factors associated with male involvement in reproductive care in Bangladesh. BMC Public Health. 2017.

34. Ezeanolu E, Lwelunmor J, Asaolu J, Obiefune M, Ezeanolu C, Osuiji A. Impact of male partner's awareness and support for contraceptives on females intent to use contraceptives in Southeast Nigeria. BMC Public Health. 2015;15:859.
Open Access Journal of Contraception

\section{Publish your work in this journal}

Open Access Journal of Contraception is an international, peerreviewed, open access, online journal, publishing original research, reports, reviews and commentaries on all areas of contraception. In addition to clinical research, demographics and health-related aspects, the journal welcomes new findings in animal and preclinical studies relating to understanding the biological mechanisms and practical development of new contraceptive agents. The manuscript management system is completely online and includes a very quick and fair peer-review system. Visit http://www.dovepress.com/testimonials. php to read real quotes from published authors. 